\title{
Superiority of "triple" therapy with salmeterol/ fluticasone propionate and tiotropium bromide versus individual components in moderate to severe COPD
}

\author{
D Singh, ${ }^{1}$ J Brooks, ${ }^{2}$ G Hagan, ${ }^{3}$ A Cahn, ${ }^{4}$ B J O'Connor ${ }^{5}$
}

\begin{abstract}
${ }^{1}$ Medicines Evaluation Unit, University Hospital of South Manchester/University of

Manchester, Manchester, UK;

${ }^{2}$ Statistics and Programming,

GlaxoSmithKline R\&D, Greenford, UK: ${ }^{3}$ Respiratory MDC,

GlaxoSmithKline R\&D, Greenford, UK; ${ }^{4}$ Clinical Pharmacology and Discovery Medicine,

GlaxoSmithKline RgD, Greenford, UK; ${ }^{5}$ Department of Respiratory Medicine and Allergy, Guy's,

King's and St Thomas' School of

Medicine, London, UK

Correspondence to:

Dr D Singh, Medicines

Evaluation Unit, University

Hospital of South Manchester,

Manchester M33 3TR, UK;

dsingh@meu.org.uk
\end{abstract}

Received 12 July 2007

Accepted 23 December 2007

Published Online First

1 February 2008

\begin{abstract}
Background: The combination of salmeterol and fluticasone propionate (SFC) and tiotropium bromide (TIO) are commonly used treatments in chronic obstructive pulmonary disease (COPD) but there are few data on their effectiveness when used together. We compared the effects of SFC $50 / 500 \mu \mathrm{g}$ twice daily in addition to TIO $18 \mu \mathrm{g}$ once daily with the individual treatments alone.

Methods: 41 patients with COPD participated in a randomised, double blind, double dummy, three way crossover study with 2 week washout periods between treatments. Lung function assessment included plethysmography and spirometry. The primary end point was post-dose specific airways conductance (sGaw) area under the curve $\left(\mathrm{AUC}_{0-4} \mathrm{~h}\right)$ on day 14.
\end{abstract}

Results: $\mathrm{AUC}_{0-4} \mathrm{~h}$ SGaw was significantly higher on day 14 after SFC+TIO compared with TIO (22\%) or SFC alone $(27 \%)$ (both $p<0.001)$. SFC+TIO significantly improved trough forced expiratory volume in $1 \mathrm{~s}$ compared with TIO alone $(212 \mathrm{ml}, \mathrm{p}<0.001)$ and SFC alone $(110 \mathrm{ml}$, $p=0.017$ ) on day 14 . Inspiratory capacity measurements also showed significant benefits for triple therapy over individual components on day 14 . Subjects receiving SFC+TIO had clinically relevant improvements in Transition Dyspnoea Index (TDI) total score of 2.2 compared with TIO alone $(p<0.001)$ (but not SFC alone, 0.7; NS) and used significantly less rescue medication (1.0 occasion less daily than TIO $(p<0.001)$ and 0.6 less than SFC $(p=0.01))$

Conclusion: SFC+TIO triple therapy led to greater improvements in bronchodilation compared with $\mathrm{TIO}$ and SFC alone. The advantages of triple therapy are observed across a range of physiologically important parameters, including airway conductance and lung volumes. Triple therapy also led to patient related benefits by improving TDI and use of rescue medication.

Trial registration number: NCT00325169.

Chronic obstructive pulmonary disease (COPD) is a multi-component disease with inflammation playing a key role, even in the early stages. ${ }^{1}$ It is characterised by airflow obstruction that is both progressive and poorly reversible. ${ }^{2}$ Drug treatments for COPD aim to control symptoms, maximise pulmonary function and reduce exacerbation rates. ${ }^{2}$ The inhaled anticholinergic tiotropium (TIO) provides effective bronchodilation over $24 \mathrm{~h}$ and reduces symptoms. ${ }^{3}{ }^{4}$ These effects are associated with a reduction in exacerbation rates. ${ }^{5}$ The long acting beta agonist (LABA) salmeterol is an alternative inhaled bronchodilator therapy and is often prescribed in a combination inhaler with the anti-inflammatory corticosteroid fluticasone propionate (FP). ${ }^{6-9}$ This combination of salmeterol and FP (SFC) has demonstrated a broad range of anti-inflammatory effects ${ }^{10}$ that are greater than those seen with inhaled corticosteroid (ICS) monotherapy ${ }^{11}$ and the likely explanation for this is a molecular interaction (synergy) between the LABA and ICS. $^{12}$ The anti-inflammatory and bronchodilator effects of SFC provides greater symptom control, pulmonary function improvement and exacerbation reduction compared with either of the individual component treatments. ${ }^{9}$

Current COPD guidelines recommend that long acting bronchodilators should be used in patients who are symptomatic despite therapy with short acting bronchodilators. ICS therapy is reserved for patients with a forced expiratory volume in $1 \mathrm{~s}$ $\left(\mathrm{FEV}_{1}\right)$ of $\leqslant 50 \%$ predicted, who are having two or more exacerbations requiring treatment with antibiotics or oral corticosteroids in a 12 month period. ${ }^{2} 13$ "Triple therapy" with long acting anticholinergics, LABA and ICS is widely used in clinical practice. The components of triple therapy have different molecular mechanisms of action, so there is a good rationale for the use of these drugs together to maximise clinical benefits. ${ }^{14-16}$ However, there is limited evidence to support the superiority of triple therapy over other combinations. In a 1 year study in patients with COPD, "triple therapy" with TIO plus SFC was compared with TIO plus salmeterol or TIO alone, and found to be the most effective therapy in terms of improvement in pulmonary function and symptom control. ${ }^{16}$ Additionally, a pilot study in patients with severe COPD showed a benefit for triple therapy over SFC alone and TIO alone for pre-dose morning $\mathrm{FEV}_{1}$ at 3 months. ${ }^{17} \mathrm{~A}$ formal power calculation for this pilot study does not appear to have been performed, and the authors state that false negative results for lung function changes at earlier time points may be attributed to insufficient statistical power. Properly statistically powered studies are needed to fully define the pulmonary function advantages of triple therapy when compared with SFC alone and TIO alone. Information regarding the effects of triple therapy on measurements of both airflow obstruction and hyperinflation are needed.

Here we report a double blind, placebo controlled, crossover study in patients with COPD evaluating the effects of triple therapy for 2 weeks with SFC and TIO compared with treatment with SFC alone and TIO alone. We assessed whether triple therapy had pulmonary function benefits after the first dose, or whether this effect occurred 
only after 14 days of therapy. We used the sensitive pulmonary function measurement of specific airway conductance as the primary end point to compare the different treatment regimens. ${ }^{18-21}$ Pulmonary function measurements of spirometry and lung volumes were also performed, and symptom scores were evaluated.

\section{METHODS \\ Patient population}

Patients were recruited between December 2005 and August 2006 in five centres from the UK and Belgium. We recruited patients with COPD diagnosed according to current guidelines. Patients were required to meet the following inclusion criteria: aged $40-80$ years, smoking history of $\geqslant 10$ pack years, postbronchodilator $\mathrm{FEV}_{1}>30 \%$ to $\leqslant 75 \%$ predicted normal, postbronchodilator $\mathrm{FEV}_{1}$ /forced vital capacity (FVC) ratio $\leqslant 70 \%$ and a minimum score of $\geqslant 2$ on the modified Medical Research Council Dyspnoea Scale. Exclusion criteria were a diagnosis of asthma, any respiratory disorder other than COPD, previous lung surgery, current pulmonary rehabilitation, regular long term oxygen use $\geqslant 12 \mathrm{~h}$ per day, exacerbation or use of parenteral or oral steroids or change in COPD medication in the 4 weeks before randomisation, a course of antibiotics in the 8 weeks before randomisation and hospitalisation within the past year for an exacerbation. All patients gave written informed consent and the study protocol was approved by the appropriate institutional review boards and conducted in accordance with good clinical practice guidelines and the 1996 version of the Declaration of Helsinki.

\section{Study design}

This was a randomised, double blind, double dummy, three way crossover study. Patients entered a 2 week washout period at the start of which they discontinued all existing COPD medications. Eligible patients were then randomised to one of

Table 1 Baseline characteristics of the modified intention-to-treat population

\begin{tabular}{ll}
\hline Characteristic & $\begin{array}{l}\text { MITT population } \\
\text { (n= 30) }\end{array}$ \\
\hline Sex (F/M) (n (\%)) & $7(23) / 23(77)$ \\
Age (y) (mean (range)) & $62.7(45-79)$ \\
Smoking history (current/former) (n (\%)) & $14(47) / 6(53)$ \\
Pack-years (mean (range)) & $46.4(12-120)$ \\
Exacerbations in last year (mean (range)) & \\
Managed without requiring OCS/AB & $0.2(0-3)$ \\
Requiring OCS/AB & $0.2(0-2)$ \\
Requiring hospitalisation in last year & $0.0(0-1)$ \\
FEV predicted normal (mean (range)) & $47.1(27.2$ to 66.0$)$ \\
\% Reversibility of predicted normal (mean (range)) & $6.78(-3.1$ to 19.9) \\
mMRC dyspnoea score (n (\%)) & $21(70)$ \\
Grade 2 & $9(30)$ \\
Grade 3 & $6.3(1.73)$ \\
BDI (mean (SD)) & $23(77)$ \\
COPD medication pre-study (n (\%)) & $11(37)$ \\
Salmeterol & $10(33)$ \\
Fluticasone propionate & $5(17)$ \\
Budesonide & $1(3)$ \\
Beclomethasone & $4(13)$ \\
Formoterol & $11(37)$ \\
Tiotropium &
\end{tabular}

$A B$, antibiotics; $B D I$, Baseline Dyspnoea Index; COPD, chronic obstructive pulmonary disease; $\mathrm{FEV}_{1}$, forced expiratory volume in $1 \mathrm{~s}$; MITT, modified intent to treat; $\mathrm{mMRC}$, modified Medical Research Council; OCS, oral corticosteroids. six treatment sequences. Each patient received all three treatment options of SFC 50/500 $\mu \mathrm{g}$ twice daily, TIO $18 \mu \mathrm{g}$ once daily or SFC 50/500 $\mu \mathrm{g}$ twice daily plus TIO $18 \mu \mathrm{g}$ once daily for 2 weeks in a randomised double blinded fashion. There were 2 week washout periods between treatment periods. After randomisation, the only medication allowed in addition to the study medication was salbutamol for relief therapy. Patients could also take smoking cessation therapy if required. Pulmonary function measurements were performed on the first day of each treatment period (day 1) and on day 14. Patients were asked to withhold rescue salbutamol for $6 \mathrm{~h}$ prior to the visit on days 1 and 14 .

The total study duration was 13 weeks. Post-randomisation, patients were reviewed for safety purposes every 2 weeks for 10 weeks and patients attended a final visit 1 week after the end of treatment or study withdrawal. Double blind study medication was provided as matched Diskus/Accuhaler inhalers (GlaxoSmithKline, UK) and Handihalers (Boehringer Ingelheim, Germany). Treatment compliance was assessed at each post-treatment study visit by recording the number of doses remaining in each returned Diskus/Accuhaler inhaler and the number of capsules returned.

\section{Pulmonary function}

During each treatment period, body plethysmography measurements of specific airway conductance (sGaw) were performed before the first administration of study drug on day 1 , and then at 30, 75, 120 and 240 min post-dose. This was repeated on day 14. Spirometric measurements of $\mathrm{FEV}_{1}$ and FVC were performed pre-dose (trough value) on days 1 and 14, and also at $2 \mathrm{~h}$ and $4 \mathrm{~h}$ post-dose. Inspiratory capacity (IC), residual volume (RV) and total lung capacity (TLC) measurements were also obtained at these time points. sGaw, functional residual capacity, vital capacity and IC were measured in a constant volume plethysmograph (Sensormedics Vmax 6200). TLC and RV were then calculated from these parameters. Body plethysmograph measurements were performed in triplicate and the mean used for analysis.

\section{Diary cards and symptoms}

Patients were given daily record cards to measure morning peak expiratory flow (PEF) and the number of occasions they used rescue medication over a $24 \mathrm{~h}$ period. The Baseline Dyspnoea Index was recorded at the end of the run-in, and the Transition Dyspnoea Index (TDI) score was assessed by study staff on day 14 of each treatment period.

\section{Safety}

Safety was assessed at each clinic visit by documenting all adverse events and measuring vital signs.

\section{Statistical methods}

The treatment comparisons, which were considered of equal importance, were SFC+TIO versus $\mathrm{TIO}$ and SFC+TIO versus SFC. Based on previous data, ${ }^{18}$ a treatment decrease of $15 \%$ in sGaw on the individual treatments compared with the combination was defined as clinically relevant. To detect a decrease of $15 \%$ in $\mathrm{AUC}_{(0-4 \mathrm{~h})}$ sGaw between one of the individual treatments and SFC+TIO with $90 \%$ power, a two sided 0.025 significance level and a within subject SD of 0.1652 (log transformed sGaw), it was estimated that 30 subjects would be required to complete at least two active treatment periods. The primary population for the analysis of efficacy was 
Figure 1 Flowchart of patients through the study. MITT, modified intention-totreat; SFC, salmeterol/fluticasone propionate combination; TIO, tiotropium bromide. * Subjects who, during each of at least two treatment periods, received at least one dose of study treatment and completed the baseline and at least one post-treatment efficacy assessment.

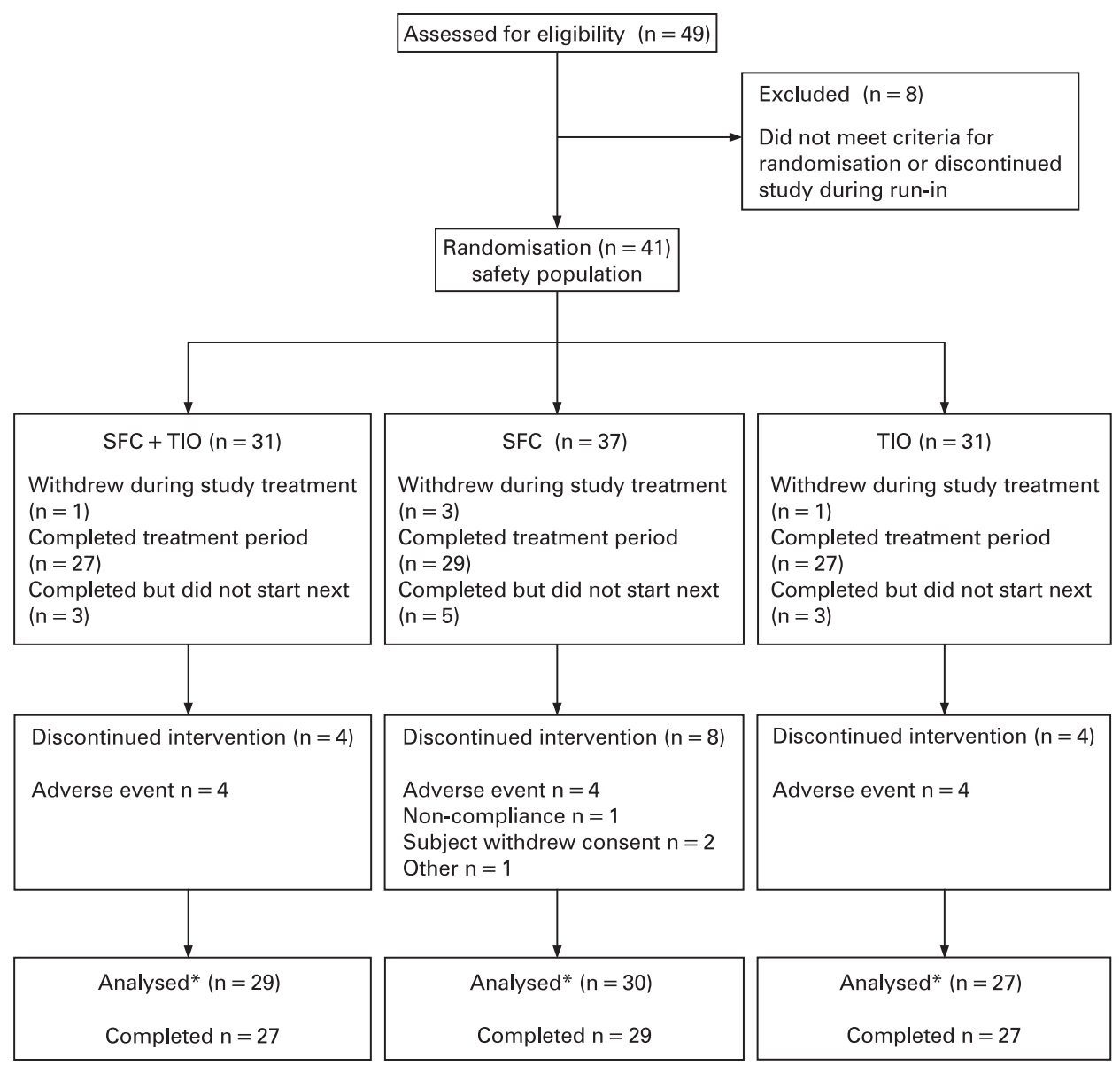

the modified intention-to-treat (MITT) population and this was used for the analysis of all efficacy end points. The MITT population comprised all subjects who were randomised and who, during each of at least two treatment periods, received at least one dose of study treatment and completed the baseline and at least one post-treatment efficacy assessment.

The primary efficacy end point was specific airway conductance $\mathrm{AUC}_{(0-4}$ h) sGaw on day 14. sGaw $\mathrm{AUC}_{(0-4 \text { h) }}$ was log transformed and then analysed using a mixed model with treatment, period, baseline and mean baseline included as fixed effects, and subject fitted as a random effect. Analyses were adjusted for baseline (the pre-dose value on day 1) and mean baseline (the mean of the three baselines for each subject) to account for the subject's status at the beginning of each treatment. The Kenward and Roger method ${ }^{22}$ for approximating the denominator degrees of freedom and correcting for bias in the estimated variance-covariance matrix of the fixed effects was used.

Treatment ratios for the comparison of SFC+TIO with each individual treatment ( $\mathrm{TIO}$ and SFC) were calculated by taking the anti-log of the difference between least square means, and $97.5 \%$ confidence interval (CI) was calculated using pooled estimates of variance for the difference and then anti-logged for reporting. Adjusted means and differences in logged data were thus converted to geometric mean ratios. An adjusted geometric mean ratio would be exactly equal to 1 if there was no difference between the treatments or time points compared. A value higher than 1 indicates a positive difference and a value less than 1 a negative difference.

The $97.5 \%$ CI was used to draw conclusions regarding the relative efficacy of the treatments in order to account for the two equally important treatment comparisons, with a $\mathrm{p}$ value of $\leqslant 0.025$ being significant. The 2 week washout period between treatment periods was considered sufficient to ensure subjects were in a similar condition at the start of each treatment period. Treatment by period interaction and carryover effects were not formally investigated. Secondary end points included $\mathrm{FEV}_{1}, \mathrm{FVC}, \mathrm{IC}, \mathrm{RV}$ and TLC, and were analysed in a similar way to the primary efficacy parameter, although $\mathrm{FEV}_{1}$ and $\mathrm{FVC}$ were not log transformed prior to analysis.

The TDI total score, mean morning PEF and the mean number of occasions salbutamol was used as rescue medication in a $24 \mathrm{~h}$ period were analysed using a mixed model with treatment and period as fixed effects and subject as a random effect.

\section{RESULTS}

Of 49 patients screened, 41 were randomised to treatment and received at least one dose of medication. Of those randomised, 30 subjects comprised the MITT population for efficacy analysis, with a total of $25(61 \%)$ patients completing all treatment periods. Details of patient baseline characteristics are shown in table 1 and the flow of patients through the study with reasons for discontinuation are shown in fig 1 . During each treatment period, compliance with study medication was $\geqslant 93 \%$ and similar in all treatment periods.

\section{Day 14 pulmonary function}

sGaw

Analysis of $\mathrm{AUC}_{(0-4 \mathrm{~h})}$ for sGaw after the morning dose of study medication showed that the SFC+TIO combination was 

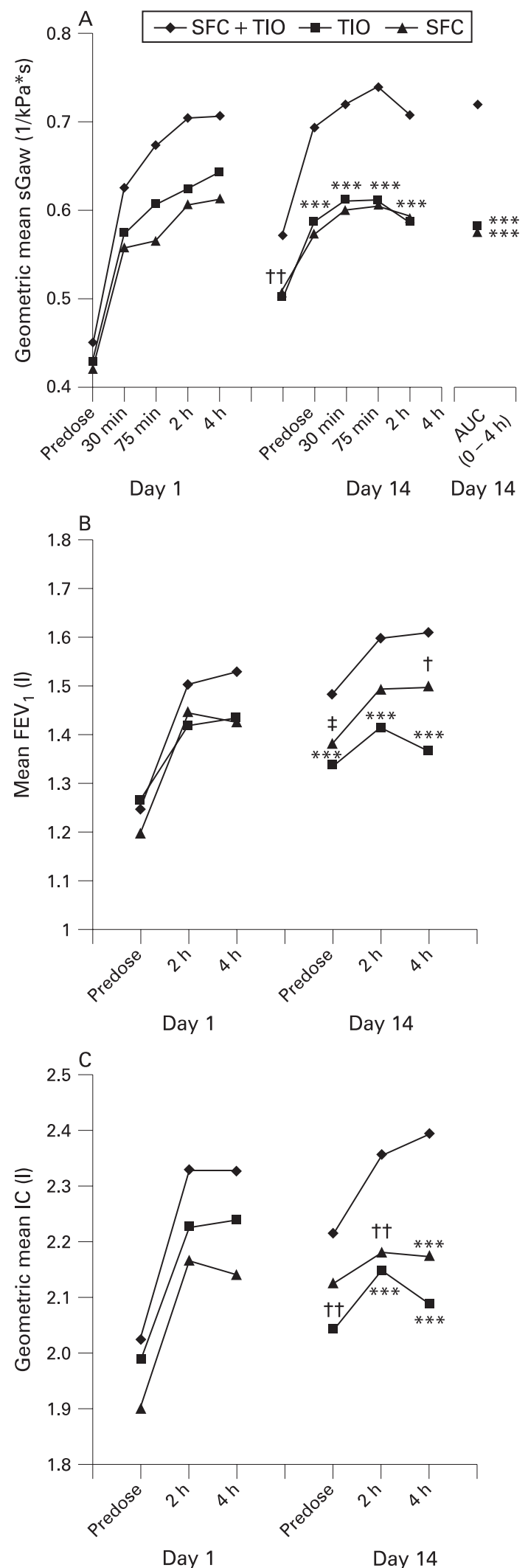

Figure 2 (A) Specific airways conductance (sGaw), (B) forced expiratory volume in $1 \mathrm{~s}\left(\mathrm{FEV}_{1}\right)$ and $(\mathrm{C})$ inspiratory capacity (IC) on day 1 and day 14 of treatment. SFC, salmeterol/fluticasone propionate combination; TIO, tiotropium bromide. (A) ${ }^{* *} \mathrm{p}<0.001 \mathrm{SFC}+\mathrm{TIO}$ vs TIO and vs SFC; $\dagger \dagger p=0.002$ SFC+TIO vs TIO and vs SFC. (B) ${ }^{* *} \mathrm{p}<0.001$ SFC+TIO vs TIO; $† p=0.023$ SFC + TIO vs SFC; $t p=0.017$ SFC+TIO vs SFC. (C) ${ }^{* * *} p<0.001$ SFC+TIO vs TIO and vs SFC; $\dagger \dagger p=0.004$ SFC+TIO vs TIO and vs SFC. significantly more effective than both TIO and SFC alone in improving sGaw (fig $2 \mathrm{~A}$ ). The ratios of SFC+TIO to the individual treatments showed that the combination produced a $22 \%$ improvement in $\left.\mathrm{AUC}_{(0-4} \mathrm{h}\right)$ sGaw over TIO alone (ratio $1.22,97.5 \%$ CI 1.10 to $1.35 ; \mathrm{p}<0.001)$ and a $27 \%$ improvement over SFC alone (ratio $1.27,97.5 \%$ CI 1.14 to $1.42 ; \mathrm{p}<0.001$ ).

SFC+TIO was significantly more effective than TIO or SFC alone at improving post-dose sGaw at all time points from $30 \mathrm{~min}$ to $4 \mathrm{~h}$. At $2 \mathrm{~h}$, the ratio for SFC+TIO compared with TIO and SFC was $1.22(97.5 \%$ CI 1.09 to $1.37 ; \mathrm{p}<0.001)$ and 1.28 (97.5\% CI 1.13 to $1.44 ; \mathrm{p}<0.001)$, respectively. At $4 \mathrm{~h}$, the ratio was 1.24 (97.5\% CI 1.09 to $1.42 ; \mathrm{p}<0.001)$ and $1.27(97.5 \%$ CI 1.11 to $1.46 ; \mathrm{p}<0.001)$ compared with TIO and SFC, respectively. Similarly, SFC+TIO was significantly more effective than both TIO and SFC alone in improving the trough sGaw with a ratio compared with TIO of 1.17 (97.5\% CI 1.04 to $1.30 ; p=0.002)$ and $1.18(97.5 \%$ CI 1.05 to $1.32 ; p=0.002)$ compared with SFC.

\section{Spirometry}

A significant improvement in $\mathrm{FEV}_{1}$ was seen during treatment with SFC+TIO compared with TIO alone at both 2 and $4 \mathrm{~h}$ post-dose (198 $\mathrm{ml}$ at $2 \mathrm{~h}, \mathrm{p}<0.001 ; 251 \mathrm{ml}$ at $4 \mathrm{~h}, \mathrm{p}<0.001)$, and SFC alone, reaching statistical significance at $4 \mathrm{~h}(97 \mathrm{ml}$; $\mathrm{p}=0.023)$ but not at $2 \mathrm{~h}(93 \mathrm{ml} ; \mathrm{p}=0.029)$ (fig $2 \mathrm{~B})$. There were also significant improvements in post-dose FVC for SFC+TIO compared with TIO and SFC alone (table 2). There was a statistically significant improvement in pre-dose (trough) $\mathrm{FEV}_{1}$ for SFC+TIO compared with TIO alone $(212 \mathrm{ml}$; $\mathrm{p}<0.001)$ and SFC alone (110 ml; $p=0.017)$ (fig 3). There was also a significant improvement in pre-dose FVC for SFC+TIO compared with TIO but not compared with SFC alone (table 3).

\section{Lung volumes}

There were significant improvements in post-dose IC and RV on day 14 for SFC+TIO compared with TIO and SFC alone, as shown in table 2, but not for TLC. The post-dose IC data are shown in fig 2C. There were also statistically significant improvements for SFC+TIO compared with TIO alone for pre-dose IC and RV (table 3). There was no difference in these parameters between SFC+TIO and SFC alone.

\section{Day 1 pulmonary function \\ sGaw}

There were improvements in sGaw on day 1 after all three treatments (fig 2A). There was no statistically significant difference between SFC+TIO and the individual components.

\section{Spirometry and lung volumes}

The improvements after SFC+TIO were not significantly different to those observed with the individual components for $\mathrm{FEV}_{1}$ (fig 2B), IC (fig 2C) and TLC (table 2). Only FVC and RV showed some evidence of a benefit in favour of SFC+TIO compared with the individual components (table 2).

\section{Diary cards and TDI score}

The daily record cards and TDI results are shown in table 4. There was a significant difference in the total TDI score between SFC+TIO and TIO at day 14 (2.2 units; $\mathrm{p}<0.001)$ but no difference between SFC+TIO and SFC alone (0.7 units, $p=0.24)$. For morning PEF, there was no statistically significant difference between SFC+TIO and either TIO alone or SFC alone. For rescue medication, the SFC+TIO group used 
Table 2 Post-dose lung function parameters at 2 and $4 \mathrm{~h}$

\begin{tabular}{|c|c|c|c|c|}
\hline & \multicolumn{2}{|l|}{$2 \mathrm{~h}$} & \multicolumn{2}{|l|}{$4 \mathrm{~h}$} \\
\hline & Triple vs TIO & Triple vs SFC & Triple vs TIO & Triple vs SFC \\
\hline \multicolumn{5}{|l|}{ Day 1} \\
\hline FVC & $0.20(0.05,0.36) ; p=0.004$ & $0.09(-0.07,0.25) ; p=0.206$ & $0.22(0.07,0.37) ; p=0.002$ & $0.20(0.04,0.36): p=0.005$ \\
\hline IC & $1.03(0.97,1.09) ; p=0.345$ & $1.04(0.98,1.11) ; p=0.152$ & $1.02(0.96,1.08) ; p=0.472$ & $1.05(0.98,1.12) ; p=0.065$ \\
\hline RV & $0.99(0.94,1.03) ; p=0.481$ & $0.99(0.94,1.04) ; p=0.604$ & $0.92(0.88,0.97) ; p<0.001$ & $0.95(0.90,1.009) ; p=0.017$ \\
\hline $\mathrm{FEV}_{1}$ & $0.20(0.10,0.30) ; p<0.001$ & $0.09(-0.003,0.19) ; p=0.029$ & $0.25(0.15,0.35) ; \mathrm{P}<0.001$ & $0.10(0.002,0.19) ; p=0.023$ \\
\hline FVC & $0.30(0.12,0.48) ; \mathrm{p}<0.001$ & $0.21(0.03,0.39) ; p=0.010$ & $0.45(0.27,0.63) ; p<0.001$ & $0.22(0.04,0.41) ; p=0.007$ \\
\hline IC & $1.10(1.04,1.17) ; p<0.001$ & $1.08(1.02,1.15) ; p=0.004$ & $1.15(1.08,1.22) ; \mathrm{p}<0.001$ & $1.10(1.04,1.17) ; p<0.001$ \\
\hline RV & $0.90(0.85,0.95) ; p<0.001$ & $0.94(0.89,1.00) ; p=0.022$ & $0.91(0.86,0.96) ; p<0.001$ & $0.96(0.90,1.02) ; p=0.092$ \\
\hline TLC & $1.00(0.98,1.02) ; p=0.706$ & $1.01(0.99,1.03) ; p=0.499$ & $1.01(0.99,1.03) ; p=0.191$ & $1.01(0.99,1.03) ; p=0.373$ \\
\hline
\end{tabular}

For $\mathrm{FEV}_{1}$, figures represent treatment differences with $97.5 \% \mathrm{Cl}$ and $\mathrm{p}$ values; for IC, RV and TLC, figures represent a treatment ratio with $97.5 \% \mathrm{Cl}$ and $\mathrm{p}$ value. IC, Inspiratory capacity; FEV 1 , forced expiratory volume in $1 \mathrm{~s}$; FVC, forced vital capacity; RV, residual volume; SFC, salmeterol/fluticasone propionate combination; TIO, tiotropium; TLC, total lung capacity.

salbutamol on 1.0 occasion less than TIO alone in a $24 \mathrm{~h}$ period $(p<0.001)$ and on 0.6 of an occasion less than the SFC group $(\mathrm{p}=0.013)$.

\section{Safety}

The overall incidence of adverse events was comparable between the treatment groups. Four patients on each treatment were withdrawn after randomisation due to an adverse event, two of which were due to an exacerbation of COPD, one during treatment with TIO alone and one during treatment with SFC alone. The mean blood pressure and pulse rate were comparable between the treatment groups at baseline and at the end of the study (data not shown).

\section{DISCUSSION}

Triple therapy with SFC plus TIO for 14 days improved sGaw to a significantly greater degree compared with treatment with SFC alone or TIO alone. This improvement was observed for the sGaw primary end point of $\mathrm{AUC}_{(0-4 \mathrm{~h})}$, and also for the sGaw secondary end points at pre-dose (trough) and 2 and $4 \mathrm{~h}$ post-dose on day 14. Pulmonary function measurements of $\mathrm{FEV}_{1}$ confirmed the superiority of triple therapy both pre- and post-dose on day 14. There was also evidence that triple therapy caused a greater reduction in hyperinflation on day 14 compared

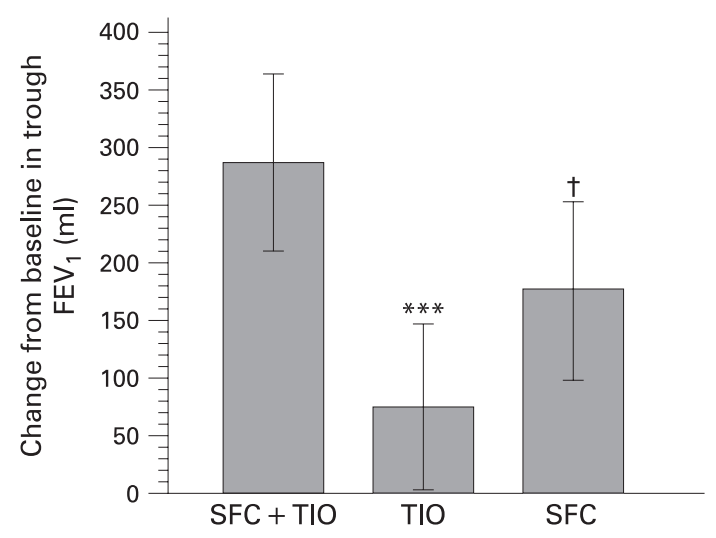

Figure 3 Change from baseline (day 1) in trough (pre-dose) forced expiratory volume in $1 \mathrm{~s}\left(\mathrm{FEV}_{1}\right)$ on day 14 . Error bars are $97.5 \% \mathrm{CI}$. SFC, salmeterol/fluticasone propionate combination; TIO, tiotropium.

${ }^{* * *} p<0.001$ SFC + TIO vs TIO; $\uparrow p=0.017$ SFC + TIO vs SFC. with treatment with SFC or TIO alone. The superiority of triple therapy demonstrated by this range of pulmonary function measurements translated into clinically important benefits in terms of symptom scores and rescue medication use, particularly compared with TIO used alone.

There are some published data regarding triple therapy in COPD. ${ }^{16}{ }^{1723}$ The novel findings of the current study are that triple therapy improves a range of pulmonary function measurements, including sGaw, $\mathrm{FEV}_{1}$ and IC, after 14 days therapy, but not after the first dose. These differences were observed both pre- and post-dose on day 14. This is the first properly statistically powered study to evaluate triple therapy with SFC and TIO compared with TIO alone and SFC alone, and we have unequivocally shown that triple therapy causes greater improvements in pulmonary function measurements that are clinically relevant.

The measurement of sGaw by body plethsymography is a sensitive way of measuring the effects of drugs in patients with asthma and COPD. ${ }^{18-21} \mathrm{FEV}_{1}$ is the most commonly used pulmonary function measurement in COPD clinical trials, as it is required by regulatory authorities and is a simple and reproducible technique to perform. However, even when taking the increased variability of sGaw into account, sGaw is still a more sensitive method of detecting changes in lung function than $\mathrm{FEV}_{1}$ in patients with COPD. ${ }^{18} 20$ Increased airway conductance, assessed by sGaw, is associated with improved expiratory airflow, assessed by $\mathrm{FEV}_{1}$, in patients with COPD. ${ }^{18} 20$ However, $\mathrm{FEV}_{1}$ can be relatively insensitive to treatment effects in patients with COPD, so large sample sizes are often needed to compare treatments based on $\mathrm{FEV}_{1}$. In contrast, sGaw measurements more readily change with improvements in airway function, so studies can be designed using smaller sample sizes based on this measurement. ${ }^{18}{ }^{20}$ Body plethysmography also has a practical advantage as it uses tidal breathing, thus avoiding the possibility of bronchoconstriction during forced expiration in patients with airflow obstruction. ${ }^{24}$

sGaw is not routinely used in clinical trials as it requires a greater degree of operator training, and is more expensive and time consuming. We chose to use this sensitive method as the primary end point in order to maximise the power of the study to detect a difference between treatments with lower patient numbers. sGaw has not been widely used in COPD trials, and therefore it is also important to evaluate more traditional pulmonary function parameters, so we also performed 
Table 3 Trough lung function measurements on day 14 of treatment

\begin{tabular}{|c|c|c|c|c|c|}
\hline & \multicolumn{3}{|c|}{ Adjusted mean change from baseline } & \multicolumn{2}{|c|}{ Treatment differences $(97.5 \% \mathrm{Cl}, \mathrm{p}$ value $)$} \\
\hline & SFC+TIO & TIO & SFC & Triple vs TIO & Triple vs SFC \\
\hline Trough FEV 1 (I) & 0.29 & 0.08 & 0.18 & $0.21(0.109,0.315) p<0.001$ & $0.11(0.007,0.214) p=0.017$ \\
\hline \multirow[t]{2}{*}{ Trough FVC (I) } & 0.39 & 0.19 & 0.26 & $0.20(0.048,0.347) p=0.004$ & $0.13(-0.026,0.277) p=0.062$ \\
\hline & \multicolumn{5}{|c|}{ Adjusted geometric mean ratio to baseline } \\
\hline Trough IC (I) & 1.13 & 1.04 & 1.08 & $1.08(1.019,1.150) p=0.004$ & $1.05(0.982,1.112) p=0.109$ \\
\hline Trough RV (I) & 0.90 & 0.96 & 0.92 & $0.93(0.875,0.991) p=0.011$ & $0.98(0.919,1.044) p=0.459$ \\
\hline Trough TLC (I) & 1.00 & 1.00 & 1.00 & $1.00(0.980,1.026) p=0.776$ & $1.00(0.981,1.027) p=0.721$ \\
\hline
\end{tabular}

IC, Inspiratory capacity; FEV ${ }_{1}$, forced expiratory volume in $1 \mathrm{~s}$; FVC, forced vital capacity; RV, residual volume; SFC, salmeterol/ fluticasone propionate combination; TIO, tiotropium; TLC, total lung capacity.

measurements of $\mathrm{FEV}_{1}$ and lung volumes. Our study design therefore allowed a comprehensive assessment of airway conductance, airflow and lung volumes.

On day 14, both sGaw and $\mathrm{FEV}_{1}$ data showed that triple therapy was superior to SFC alone or TIO alone. This superiority was observed both pre-dose and in the $4 \mathrm{~h}$ postdose. These pre-dose measurements are indicative of the cumulative effects of 13 days of treatment, rather than the acute effects of treatment. We can infer that the superiority of triple therapy over the other treatments after multiple dosing was present throughout the $24 \mathrm{~h}$ period post-dose, and not just immediately post-dose. The day 14 pre-dose $\mathrm{FEV}_{1}$ data allow the magnitude of this effect to be fully appreciated; triple therapy had a superiority of $212 \mathrm{ml}$ over TIO and $110 \mathrm{ml}$ over SFC. The accompanying changes in TDI scores and rescue medication use demonstrate that these differences are also clinically relevant.

IC is a widely used measurement of pulmonary hyperinflation that can be related to the degree of breathlessness that patients suffer. ${ }^{25}$ Our findings on day 14 post-dose demonstrate a greater increase in IC with triple therapy compared with the other treatments. SFC therapy alone $e^{26}$ and TIO alone ${ }^{27}$ are known to increase IC, and hence reduce hyperinflation, leading to improvements in exercise capacity. We have shown that greater increases in IC can be achieved when both of these inhalers are used together, compared with the individual treatments, and accordingly would expect this to translate into further improvements in exercise capacity. This warrants further study.

At pre-dose on day 14, the effects of triple therapy on IC and RV were significantly greater than TIO, but not compared with SFC. Interestingly, data also showed that triple therapy was superior to treatment with TIO alone for TDI score, but not compared with SFC. The current study was not statistically powered to evaluate TDI scores, but our findings are suggestive that changes in TDI scores were determined by the degree of hyperinflation throughout the $24 \mathrm{~h}$ period, rather than just in the $4 \mathrm{~h}$ after dosing. In this respect, triple therapy may not have any advantage over treatment with SFC alone.

Our study was focused on day 14 to compare the effects of the different treatments after multiple dosing. We also measured pulmonary function after the first dose, and found no advantage of triple therapy compared with the other treatments for the key measurements of sGaw, $\mathrm{FEV}_{1}$ and IC. There was some evidence of triple therapy superiority for FVC, but overall the pulmonary function data indicated no difference. The major advantages of triple therapy compared with TIO alone or SFC alone appears therefore to be a cumulative effect resulting from repeat dosing and can already be observed after 2 weeks of therapy.

We did not recruit patients based on specific reversibility criteria. Accordingly, our results are probably applicable to patients with COPD generally, and not confined to a subgroup with specific characteristics. Our study should encourage further research to evaluate the potential of triple therapy on clinically relevant end points. Aaron et al showed that SFC (50/500 $\mu \mathrm{g}$ twice daily) plus TIO (18 $\mu \mathrm{g}$ once daily) was superior to TIO alone in terms of pulmonary function and symptoms over 1 year, and results for TIO plus salmeterol (50 $\mu$ g twice daily) were similar to TIO alone. ${ }^{16}$ The primary end point of this study was exacerbations, but the number of subjects was too small to provide adequate statistical power for the observed treatment difference. The pulmonary function findings of the superiority of triple therapy compared with TIO alone agree with the findings of the current study. Cazzola et al evaluated the same three treatment arms as the current study, but in a parallel group design based on the primary end point of $\mathrm{FEV}_{1}$, and reported data that agrees with the current study at 3 months,

Table 4 Patient recorded diary card assessments and Transitional Dyspnoea Index scores

\begin{tabular}{|c|c|c|c|c|c|c|}
\hline \multirow[b]{2}{*}{ Parameter } & \multirow[b]{2}{*}{ Baseline } & \multicolumn{3}{|c|}{ Treatment value at day 14} & \multicolumn{2}{|c|}{ Treatment differences $(97.5 \% \mathrm{CI}) ; \mathrm{p}$ value } \\
\hline & & SFC+TIO & TIO & SFC & Triple vs TIO & Triple vs SFC \\
\hline Mean (SD) TDI total score & $6.3(1.73)$ & $2.3(2.55)$ & $0.2(3.09)$ & $1.7(2.76)$ & $\begin{array}{l}2.2(0.8,3.5) \\
p<0.001\end{array}$ & $\begin{array}{l}0.7(-0.7,2.1) \\
p=0.238\end{array}$ \\
\hline Improvement: TDI $\geqslant 1$ (n (\%)) & & $21(72)$ & $8(27)$ & $14(54)$ & & \\
\hline No change: $T D I=0$ & & $6(21)$ & $15(50)$ & $9(35)$ & & \\
\hline Deterioration: $\mathrm{TDI} \leqslant-1$ & & $2(7)$ & $7(23)$ & $3(12)$ & & \\
\hline \multirow[t]{2}{*}{$\begin{array}{l}\text { Mean (SD) occasions of rescue } \\
\text { medication use over } 24 \mathrm{~h}\end{array}$} & $3.2(2.64)$ & $1.6(1.60)$ & $2.6(2.50)$ & $2.0(2.23)$ & $\begin{array}{l}-1.0(-1.5,-0.6) \\
p<0.001\end{array}$ & $\begin{array}{l}-0.6(-1.1,-0.1) ; \\
p=0.013\end{array}$ \\
\hline & & & & & \multicolumn{2}{|c|}{ Treatment differences (SE); p value } \\
\hline $\begin{array}{l}\text { Mean (SD) morning PEF } \\
\text { (treatment period) }\end{array}$ & $221.4(84.8)$ & $265.8(99.2)$ & $244.2(101.2)$ & $249.1(91.0)$ & $\begin{array}{l}14.9(-0.4,30.3) \\
p=0.029\end{array}$ & $\begin{array}{l}11.0(-5.1,27.1) \\
p=0.121\end{array}$ \\
\hline
\end{tabular}

PEF, peak expiratory flow; SFC, salmeterol/fluticasone propionate combination; TDI, Transitional Dyspnoea Index; TIO, tiotropium. 
but not at earlier time points. ${ }^{17}$ Villar and Pombo reported a crossover study in patients on continual treatment with inhaled FP $(500 \mu \mathrm{g} / 12 \mathrm{~h})$, comparing 1 week of therapy with FP plus salmeterol $(50 \mu \mathrm{g} / 12 \mathrm{~h})$ versus FP plus TIO $(18 \mu \mathrm{g} / 24 \mathrm{~h})$ versus FP plus TIO plus salmeterol. ${ }^{23}$ There was a triple therapy arm (concurrent therapy with free combination FP plus TIO plus salmeterol), but it is important to note that the combination inhaler SFC was not used. Triple therapy was found to have the greatest effect on $\mathrm{FEV}_{1}$. Comparison of triple therapy with FP plus salmeterol agrees with the current study findings. However, we used the SFC combination inhaler which has been shown to have superior effects on pulmonary function compared with the individual inhalers in asthma. ${ }^{28}$ Nevertheless, these previous publications in conjunction with the current study provide a strong case that triple therapy is the best way of optimising pulmonary function in patients with COPD of an appropriate severity.

Triple therapy is widely used in clinical practice for patients with COPD to optimise lung function, improve symptoms and reduce exacerbations. However, the evidence base for this approach is limited. The current study provides an important addition to our knowledge, proving that triple therapy with SFC plus TIO is more effective than SFC alone or TIO alone in terms of pulmonary function. Adequately powered, long term studies of the benefits of triple therapy on exacerbation rates and other clinical end points are now needed to fully justify this approach in clinical practice.

Acknowledgements: This study was funded by GlaxoSmithKline. The authors would like to thank the investigators, S D Singh (Manchester), B O'Connor (London), R Djukanovic (Southampton), W Wedzicha (London), G Joos (Gent, Belgium), who participated in the study and Diana Jones, a medical writer, who provided medical writing support sponsored by GSK.

Funding: The study was funded by an unrestricted research grant from GlaxoSmithKline.

\section{Competing interests: None.}

Ethics approval: The study protocol was approved by the appropriate institutional review boards and conducted in accordance with good clinical practice guidelines and the 1996 version of the Declaration of Helsinki (study No SC0104962).

Note from Editor-in-Chief: J A Wedzicha recruited patients to this study but was not involved in data analysis or preparation of the manuscript and was not the handling editor of this paper.

\section{REFERENCES}

1. Hogg JC, Chu F, Utokaparch S, et al. The nature of small-airway obstruction in chronic obstructive pulmonary disease. N Engl J Med 2004;350:2645-53.

2. Global strategy for the diagnosis, management, and prevention of chronic obstructive pulmonary disease. Global Initiative for Chronic Obstructive Lung Disease 2006.

3. Littner MR, llowite JS, Tashkin DP, et al. Long-acting bronchodilation with once daily dosing of tiotropium (Spiriva) in stable chronic obstructive pulmonary disease. Am J Respir Crit Care Med 2000;161:1136-42.

4. Casaburi R, Mahler DA, Jones PW, et al. A long-term evaluation of once-daily inhaled tiotropium in chronic obstructive pulmonary disease. Eur Respir $\mathrm{J}$ 2002; 19:217-24.
5. Niewoehner DE, Rice $\mathrm{K}$, Cote $\mathrm{C}$, et al. Prevention of exacerbations of chronic obstructive pulmonary disease with tiotropium, a once-daily inhaled anticholinergic bronchodilator: a randomized trial. Ann Intern Med 2005:143:317-26.

6. Mahler DA, Wire P, Horstman D, et al. Effectiveness of fluticasone propionate and salmeterol combination delivered via the Diskus device in the treatment of chronic obstructive pulmonary disease. Am J Respir Crit Care Med 2002;166:1084-91.

7. Calverley PMA, Pauwels R, Vestbo J, et al. Combined salmeterol and fluticasone in the treatment of chronic obstructive pulmonary disease: a randomised controlled trial. Lancet 2003;361:449-56.

8. Hanania NA, Darken P, Horstman D, et al. The efficacy and safety of fluticasone propionate $(250 \mu \mathrm{g}) / \mathrm{salmeterol}(50 \mu \mathrm{g})$ combined in the Diskus inhaler for the treatment of COPD. Chest 2003;124:834-43.

9. Calverley PMA, Anderson JA, Celli B, et al. Salmeterol and fluticasone propionate and survival in chronic obstructive pulmonary disease. $N$ Engl $\mathrm{J}$ Med 2007;356:775-89.

10. Barnes NC, Qiu YS, Pavord ID, et al. Anti inflammatory effects of salmeterol/ fluticasone propionate in chronic obstructive lung disease. Am J Respir Crit Care Med 2006;173:736-43.

11. Bourbeau J, Christodoulopoulos P, Maltais F, et al. Effect of salmeterol/fluticasone propionate on airway inflammation in COPD: a randomized controlled trial. Thorax 2007;62:938-43.

12. Johnson M. Corticosteroids: potential beta2-agonist and anticholinergic interactions in chronic obstructive pulmonary disease. Proc Am Thorac Soc 2005;2:320-5.

13. National Institute Clinical Excellence clinical guideline. CG12. Chronic Obstructive Pulmonary Disease. 2004. http://guidance.nice.org.uk/CG12/guidance (accessed 28 March 2008).

14. Cazzola M, Di Marco F, Santus P, et al. The pharmacodynamic effects of single inhaled doses of formoterol, tiotropium and their combination in patients with COPD. Pulm Pharmacol Ther 2004;17:35-9.

15. van Noord JA, Aumann J-L, Janssens E, et al. Comparison of tiotropium once daily, formoterol twice daily and both combined once daily in patients with COPD. Eur Respir J 2005;26:214-22.

16. Aaron SD, Vandemheen $\mathrm{KL}$, Fergusson D, et al. Tiotropium in combination with placebo, salmeterol, or fluticasone-salmeterol for treatment of chronic obstructive pulmonary disease. randomized trial. Ann Intern Med 2007;146:545-55.

17. Cazzola M, Andò F, Santus $\mathrm{P}$, et al. A pilot study to assess the effects of combining fluticasone propionate/salmeterol and tiotropium on the airflow obstruction of patients with severe-to-very severe COPD. Pulm Pharmacol Ther 2007;20:556-61.

18. Borrill ZL, Houghton CM, Tal-Singer R, et al. The use of plethysmography and oscillometry to compare long acting bronchodilators in patients with COPD. Br J Clin Pharmacol 2008;65:244-52.

19. Houghton $\mathbf{C M}$, Woodcock AA, Singh D. A comparison of lung function methods for assessing dose-response effects of salbutamol. Br J Clin Pharmacol 2004;58:134-41.

20. Borrill Z, Houghton C, Woodcock AA, et al. Measuring bronchodilation in COPD clinical trials. Br J Clin Pharmacol 2005;59:379-84.

21. van Noord JA, Smeets J, Clement J, et al. Assessment of reversibility of airflow obstruction. Am J Respir Crit Care Med 1994;150:551-4.

22. Kenward MG, Rogers JH. Small sample inference for fixed effects from restricted maximum likelihood. Biometrics 1997;53:983-97.

23. Villar AB, Pombo CV. Bronchodilator efficacy of combined salmeterol and tiotropium in patients with chronic obstructive pulmonary disease. Arch Bronconeumol 2005:41:130-4.

24. Burns GP, Gibson GJ. A novel hypothesis to explain the bronchoconstrictor effect of deep inspiration in asthma. Thorax 2002;57:116-19.

25. O'Donnell DE, Webb, KA. Exertional breathlessness in patients with chronic airflow limitation: the role of lung hyperinflation. Am Rev Respir Dis 1993;148:1351-7.

26. O'Donnell DE, Sciurba F, Celli B, et al. Effect of fluticasone propionate/salmeterol on lung hyperinflation and exercise endurance in COPD. Chest 2006;130:647-56.

27. Maltais F, Hamilton A, Marciniuk D, et al. Improvements in symptom-limited exercise performance over $8 \mathrm{~h}$ with once-daily tiotropium in patients with COPD. Chest 2005;128:1168-78.

28. Nelson HS, Chapman KR, Pyke SD, et al. Enhanced synergy between fluticasone propionate and salmeterol inhaled from a single inhaler versus separate inhalers. J Allergy Clin Immunol 2003;112:29-36. 